Gustavo Zoio Portela ${ }^{1}$ José Mendes Ribeiro ${ }^{1}$
${ }^{1}$ Escola Nacional de Saúde Pública Sergio Arouca, Fundação Oswaldo Cruz Rua Leopoldo Bulhões 1.480. 21041-210 Rio de Janeiro RJ. gustavo.zoio@ensp.fiocruz.br

\section{A sustentabilidade econômico-financeira da Estratégia Saúde da Família em municípios de grande porte}

\author{
The economic-financial sustainability \\ of the Family Health Strategy in large municipalities
}

Abstract The universalization of basic care and commitment budget of the Ministry of Health with the Family Health Strategy (ESF) through new systematic financing incentives have been highlighted in the Brazilian health policy scenario. One of the great problems observed is the expansion of the strategy for large urban centres. This paper studies the economic-financial sustainability of ESF in Brazilian municipalities of more than 100 thousand inhabitants according to some selected indicators, considering the geographical region to which they belong, their population size and participation in Project for the Expansion and Consolidation Family Health (Proesf). Municipalities belonging to the Southeast region, more developed of the country, have on average better economic-financial performance, but lower average values of coverage of ESF. Municipalities from the North and Northeast, with the lowest average for economic-financial sustainability indicators, were the ones that made more effort to developments in the period. Thus, we observed the $d y$ namics between bigger fiscal capacity and budgetary commitment with the Health Sector for biggest municipalities and in more economically developed regions, and greater vulnerability and dependence of federative transferences for municipalities with less people, in less developed areas.

Key words Health financing, Primary Health Care, Financial sustainability
Resumo A universalização da Atenção Básica e o compromisso orçamentário do Ministério da Saúde com a Estratégia Saúde da Família (ESF) através de novos incentivos sistemáticos de financiamento têm se destacado no cenário da politica de saúde brasileira. Um dos grandes problemas é a expansão da estratégia para os grandes centros urbanos. Este artigo estuda a sustentabilidade econômico-financeira do ESF em municípios brasileiros com mais de 100 mil habitantes segundo indicadores selecionados, considerando a região geográfica a que pertencem, porte populacional e a participação no Projeto de Expansão e Consolidação Saúde da Família (Proesf). Os municípios da região Sudeste, mais desenvolvida do país, apresentam em média melhores desempenhos econômico-financeiros, porém valores médios de cobertura de ESF mais baixos. Os municípios das regiões Norte e Nordeste, com as menores médias para indicadores de sustentabilidade econômico-financeira, são os que mais fizeram esforço de evolução no período. Assim, observamos a dinâmica entre maior capacidade fiscal e de comprometimento orçamentário com o setor saúde para os municípios de maior porte e de regiões mais desenvolvidas economicamente, e maior vulnerabilidade e dependência de transferências federativas para os municípios de menor porte e em áreas menos desenvolvidas.

Palavras-chave Financiamento em saúde, Atenção Básica, Sustentabilidade financeira 


\section{Introdução}

O objetivo deste artigo é estudar a sustentabilidade econômico-financeira da Estratégia Saúde da Família (ESF) em todos os municípios brasileiros de grande porte populacional (mais de cem mil habitantes). Adotou-se como referência alguns dos indicadores formulados e aplicados por Pereira et al. ${ }^{1}$ em municípios abrangidos pelos estudos de linhas de base para avaliação do Projeto de Expansão e Consolidação Saúde da Família (Proesf) e a cobertura populacional do programa.

Diversos estudos apontam o crescente comprometimento orçamentário que o Ministério da Saúde (MS) tem assumido para com a $\mathrm{ESF}^{2-7}$. O principal objetivo consiste na expansão da estratégia para os grandes centros urbanos, haja vista que a implantação da ESF ocorreu de forma mais acelerada em municípios de pequeno porte, com baixa ou nenhuma capacidade instalada, e mais lenta em grandes centros urbanos.

Com este propósito, instituiu-se o Projeto de Expansão e Consolidação Saúde da Família, iniciativa do Ministério da Saúde apoiada pelo Banco Mundial (Bird), voltada para a organização e o fortalecimento da Atenção Básica no país por meio da qualificação do processo de trabalho e desempenho dos serviços. O seu período de implementação compreende os anos de 2002 a 2009 e subdivide-se em três componentes: componente 1 - apoio à conversão do modelo de Atenção Básica de Saúde; componente 2 - desenvolvimento de recursos humanos; componente 3 - monitoramento e avaliação.

Simultaneamente ao investimento do MS na universalização da Atenção Básica, deram-se o avanço no processo de municipalização e o estabelecimento de novas sistemáticas para o financiamento de ações e serviços de saúde, em especial aqueles referentes ao escopo da Atenção Básica.

Nessa lógica de crescente comprometimento da instância municipal, a participação relativa do governo federal no gasto público em saúde foi se tornando menor, embora ainda constitua a principal fonte, com crescente volume de recursos gastos ao longo dos anos ${ }^{4}$.

A reorientação do Sistema Público de Saúde de seu caráter "estadualista" para a "municipalização" como eixo condutor do processo de descentralização do sistema culminou em uma série de normas operacionais básicas (NOBs) que estruturaram a alocação de recursos no âmbito do Sistema Único de Saúde (SUS) ${ }^{5}$.

A NOB 96, particularmente, se propôs a cristalizar o comando único do setor em nível local, aperfeiçoando os mecanismos de fluxos de financiamento, a partir da redução da remuneração contra a prestação de serviços e ampliação das transferências "fundo a fundo" com base na programação do uso dos recursos. Para tanto, criaram-se "níveis de gestão", aos quais os municípios responsáveis pela execução preferencial das ações e dos serviços de saúde poderiam aderir voluntariamente a um conjunto de responsabilidades e prerrogativas de gestão.

Dentre os grandes fluxos de transferências intergovernamentais conformados ao longo da implementação da NOB 96, aquele correspondente à viabilização de ações de Atenção Básica à saúde e sobre o qual faziam jus os municípios habilitados em alguma forma de gestão denominou-se Piso de Atenção Básica (PAB), constituído por duas partes: PAB fixo - direcionado aos procedimentos de assistência básica, e calculado com base em um valor per capita multiplicado pelo tamanho da população; e PAB variável destinado ao estímulo financeiro à implantação de estratégias nacionais de reorganização de modelo de atenção à saúde, dentre as quais se inclui a ESF.

Este incentivo foi determinante para o crescimento do número de equipes de Saúde da Família e evidenciou a institucionalização da ESF como parte fundamental do fortalecimento da Atenção Básica.

Alguns estudos ${ }^{2,6}$ apontam o caráter do $\mathrm{PAB}$ como política redistibutiva, uma vez que sua história tem demonstrado maior equidade na distribuição de recursos diante da heterogeneidade dos municípios brasileiros. Sustentam ainda a ideia de que a indução foi significativa, sobretudo para os municípios de menor capacidade instalada para a oferta de atenção ambulatorial básica.

Em direção oposta, Marques e Mendes ${ }^{2,3}$ e Marques e Ugá ${ }^{5}$ chamam a atenção para o fato de que o reforço do governo federal no campo da Atenção Básica significou o impedimento de municípios planejarem uma política mais adequada às necessidades locais, haja vista que ao receberem recursos para a Atenção Básica acabaram concentrando suas ações neste nível de atenção. Tal situação caracterizará o que alguns denominaram de "política tutelada da descentralização"

Esses autores ${ }^{2}$ ainda lembram que, embora os municípios contem com recursos federais, o financiamento essencial da ESF ocorre por meio de recursos próprios, que, diante da modesta receita de muitos deles, associado às limitações impostas pela Lei de Responsabilidade Fiscal às 
despesas com pessoal, enfrentam dificuldades de sustentar tais atividades. Segundo eles, tal condicionante favoreceria a capacidade de indução dos incentivos federais à política de saúde, uma vez que acabam por se traduzir na única forma dos municípios de viabilizarem novas receitas.

Outros pontos podem ser apreendidos em Marques e Mendes ${ }^{3}$, que consideram que as condições polares de gestões da NOB 96 não expressaram a heterogeneidade das redes de serviços das diferentes regiões do país, assim como em Pereira et al. ${ }^{1}$, que destacam a questão dos incentivos financeiros à ESF como um dos problemas centrais na lógica de transferências federais de recursos.

Na sequência da NOB 96, são aprovadas em 2001 e 2002 as normas operacionais de assistência à saúde (NOAS). Estas buscavam regulamentar a regionalização e hierarquização do Sistema de Saúde, em apoio à mudança do modelo assistencial e corrigindo falhas na assistência. As NOAS, todavia, mantêm o sistema de fluxos de transferências intergovernamentais configurados ao longo da implantação da NOB 96. Assim, são os incentivos financeiros (Piso da Atenção Básica Ampliada e Limites Financeiros para a Média Complexidade) que continuaram determinando a estrutura das políticas de saúde e reforçando o caráter centralizador do Sistema ${ }^{3}$.

Em 2006, o Ministério da Saúde, o Conselho Nacional de Secretários de Saúde (Conass) e o Conselho Nacional de Secretários Municipais de Saúde (Conasems) definiram o Pacto pela Saúde 2006. Esse pacto determina prioridades para a construção de políticas de saúde identificadas com as realidades regionais, define as responsabilidades sanitárias dos gestores municipais, estaduais e federal e visa ao alcance de metas nacionais e regionais, segundo as prioridades do Pacto pela Vida.

Dessa forma, o processo de habilitação de estados e municípios foi extinto. Cada ente federado (estados, municípios, Distrito Federal e União) a partir de então passou a aderir ao processo com a assinatura de um termo de compromisso de gestão, que estabelece as responsabilidades e as capacidades de cada um na oferta das ações e dos serviços de saúde.

Em que pese o esforço desta atual política na pactuação de responsabilidades entre os três gestores do SUS no campo da gestão do Sistema e da atenção à saúde, muitos dos dilemas no âmbito do financiamento da saúde aqui apontados permanecem.

Neste estudo, analisamos a estrutura de financiamento setorial dos municípios de grande porte, por série histórica e sua relação com a cobertura da $\mathrm{ESF}^{7}$.

\section{Metodologia}

Realizamos um estudo longitudinal sobre o comportamento dos municípios brasileiros de grande porte populacional quanto à sua sustentabilidade econômica e financeira na perspectiva de reorganização da atenção à saúde através da ESF.

Para fins deste trabalho, o conceito de sustentabilidade é entendido como a capacidade do municicípio em arcar em um futuro próximo com os comprometimentos políticos e financeiros vigentes para oferta dos serviços definidos como de Atenção Básica. A sustentabilidade envolve, portanto, dimensões econômicas (capacidade fiscal e transferências federativas) e comprometimento político (despesas financeiras no setor saúde).

A análise de capacidade de financiamento e a estimada sustentabilidade foram efetuadas através de dados e indicadores do Sistema de Informações sobre Orçamentos Públicos em Saúde (Siops), que tem por objetivo apurar as receitas totais e os gastos em ações e serviços públicos de saúde, assim como indicadores formulados por Pereira et al. ${ }^{1}$, todos aplicados pelos autores em 16 municípios dos estados do Amapá, Maranhão, Pará e Tocantins. Como indicador de resultado, utilizamos a adequação às metas de cobertura da ESF assumidas como compromisso no Proesf (Quadro 1).

Especificamente para o indicador "Participação da receita de impostos na receita total do município" e o indicador de resultado "Adequação ao Proesf" utilizamos séries menores: 2002 a 2006 e 2003 a 2006, respectivamente. No primeiro caso, a redução se deu pelo fato de o Siops não disponibilizar esse indicador para anos anteriores. Para o segundo a redução foi intencional, dado que o desembolso dos recursos para os municípios contemplados pelo Projeto se iniciou em 2003.

Este trabalho definiu como universo o conjunto dos 239 municípios que em 2006, segundo pesquisa no Datasus (informações provenientes do Censo 2000 e estimativas para 2001 a 2007), apresentavam um porte populacional maior do que cem mil habitantes. Neste se obteve para todos os municípios do Brasil a população residente no período de 2000 a 2006, possibilitando categorizá-los em baixo porte (100-500 mil habitantes); médio porte (500 mil a dois milhões de 
habitantes); e alto porte (mais de dois milhões de habitantes). Lembramos que esta é uma estratificação restrita a este estudo. Usualmente, os municípios de baixo e médio portes são aqueles com uma população inferior a cem mil habitan- tes. O estudo trata de todos os municípios brasileiros para o porte populacional definido e seus resultados não se generalizam aos demais.

Em seguida, foi analisada a legislação pertinente ao Proesf, na qual se obteve a lista de 204

Quadro 1. Lista de indicadores utilizados no estudo, sua descrição, forma de cálculo, fonte e critérios de mensuração e classificação das evoluções no período estudado.

\begin{tabular}{|c|c|c|c|c|}
\hline Indicadores & Descrição & Cálculo & Fonte & $\begin{array}{c}\text { Evolução no período } \\
\text { estudado }\end{array}$ \\
\hline $\begin{array}{l}\text { Participação da } \\
\text { receita de } \\
\text { impostos na } \\
\text { receita total do } \\
\text { município } \\
\text { (PRIRT) }\end{array}$ & $\begin{array}{l}\text { Capacidade } \\
\text { fiscal e } \\
\text { dependência de } \\
\text { transferências }\end{array}$ & $\begin{array}{l}\text { Impostos diretamente } \\
\text { arrecadados sobre a receita } \\
\text { total do município }\end{array}$ & Siops & $\begin{array}{l}\text { Diferença percentual do } \\
\text { indicador em } 2006 \text { sobre } \\
2002 \text { : } \\
\text { Positiva: evolução acima } \\
\text { de } 10 \% \\
\text { Conservadora: evolução } \\
\text { entre } 0 \% \text { e } 10 \% \\
\text { Negativa: evolução } \\
\text { abaixo de } 0 \%\end{array}$ \\
\hline $\begin{array}{l}\text { Participação da } \\
\text { receita própria } \\
\text { aplicada em } \\
\text { saúde (PRPAS) }\end{array}$ & $\begin{array}{l}\text { Comprometimento } \\
\text { orçamentário } \\
\text { com o setor } \\
\text { saúde }\end{array}$ & $\begin{array}{l}\text { Receita aplicada em saúde } \\
\text { sobre a receita própria do } \\
\text { município }\end{array}$ & Siops & $\begin{array}{l}\text { Diferença percentual do } \\
\text { indicador em } 2006 \text { sobre } \\
2000 \text { : } \\
\text { Positiva: evolução acima } \\
\text { de } 10 \% \\
\text { Estável: evolução entre } \\
0 \% \text { e } 10 \% \\
\text { Negativa: evolução } \\
\text { abaixo de } 0 \%\end{array}$ \\
\hline $\begin{array}{l}\text { Adequação à } \\
\text { EC } 29\end{array}$ & $\begin{array}{l}\text { Cumprimento } \\
\text { da EC } 29 / 00\end{array}$ & $\begin{array}{l}\text { Percentual da receita } \\
\text { própria aplicada na saúde } \\
\text { subtraído o percentual } \\
\text { mínimo de vinculação } \\
\text { orientado pela EC } 29 / 00^{*}\end{array}$ & Siops & $\begin{array}{l}\text { Diferença percentual do } \\
\text { indicador em } 2006 \text { sobre } \\
2000\end{array}$ \\
\hline $\begin{array}{l}\text { Despesa } \\
\text { potencial em } \\
\text { saúde per capita } \\
\text { (DPSPC) }\end{array}$ & $\begin{array}{l}\text { Valor nominal } \\
\text { para gastos em } \\
\text { saúde por } \\
\text { habitante }\end{array}$ & $\begin{array}{l}\text { Quinze por cento da receita } \\
\text { de impostos e transferências } \\
\text { constitucionais e legais per } \\
\text { capita somados às } \\
\text { transferências } \\
\text { intergovernamentais para a } \\
\text { saúde per capita }\end{array}$ & $\begin{array}{l}\text { Pereira } \\
\text { et al. }{ }^{1}\end{array}$ & $\begin{array}{l}\text { Diferença em pontos } \\
\text { percentuais do indicador } \\
\text { entre } 2006 \text { e } 2000\end{array}$ \\
\hline $\begin{array}{l}\text { Margem de } \\
\text { expansão do } \\
\text { gasto per capita } \\
\text { (MEGPC) }\end{array}$ & $\begin{array}{l}\text { Folga ou excesso } \\
\text { de gastos em } \\
\text { saúde }\end{array}$ & $\begin{array}{l}\text { Despesa potencial em saúde } \\
\text { per capita subtraída a } \\
\text { despesa total com saúde por } \\
\text { habitante }\end{array}$ & $\begin{array}{l}\text { Pereira } \\
\text { et al. }{ }^{1}\end{array}$ & $\begin{array}{l}\text { Diferença em pontos } \\
\text { percentuais do indicador } \\
\text { entre } 2006 \text { e } 2000\end{array}$ \\
\hline $\begin{array}{l}\text { Adequação ao } \\
\text { Proesf }\end{array}$ & $\begin{array}{l}\text { Padrão de } \\
\text { expansão da ESF }\end{array}$ & $\begin{array}{l}\text { Percentual de cobertura da } \\
\text { ESF no município subtraído } \\
\text { o percentual de cobertura } \\
\text { pactuado no Proesf }\end{array}$ & SIAB & $\begin{array}{l}\text { Diferença em pontos } \\
\text { percentuais do indicador } \\
\text { entre } 2006 \text { e } 2000\end{array}$ \\
\hline
\end{tabular}

Fonte: Elaboração própria.

*Parâmetros utilizados antes da sua regulamentação: 2000 (7\%); 2001 (8,60\%); 2002 (10,2\%); 2003 (11,8\%); a partir de 2004 $(15 \%) ;{ }^{* *} 100.000$ a 500.000 habitantes $(70 \%) ; 500.000$ a 200.0000 habitantes $(50 \%) ; 2.000 .000$ a 5.000 .000 habitantes (40\%); acima de 5.000 .000 habitantes $(30 \%)$. 
municípios aprovados e habilitados a participar do Projeto através de um conjunto de portarias específicas $^{8-13}$. Posteriormente, foi conferido com pesquisa no Datasus se os municípios indicados nas portarias receberam recursos provenientes do Projeto no período de 2003 a 2006. Esse critério acabou por excluir 19 municípios e agregar seis outros que não estavam listados, totalizando assim 191 municípios participantes.

De posse dessas informações, foi possível então descrever e analisar a variação no período dos indicadores, a partir da distribuição dos municípios segundo as variáveis: "Região geográfica", "Porte populacional” e "Participação no Proesf".

Neste estudo, entende-se que analisar o comportamento dos municípios para os indicadores selecionados segundo região geográfica justificase ao considerarmos as diversas disparidades econômicas e sociais inter-regiões em nosso país.

Da mesma forma, o aspecto demográfico ganha particular relevância a partir da suposição de que o tamanho populacional desses municípios também guarda uma estreita relação com a sua composição socioeconômica. Além do mais, sabe-se que a consolidação da Estratégia Saúde da Família tem se mostrado mais incipiente nos grandes centros urbanos, o que justifica a análise do comportamento dos diferentes estratos populacionais dentro do grupo de municípios com mais de cem mil habitantes, observando inclusive se essa tendência se confirma.

Já a opção por analisar comparativamente o comportamento dos municípios que participam do Proesf e os que não participam do Projeto teve como base duas premissas. Sobre a primeira, acreditamos que a participação refletiria o envolvimento institucional dos municípios no cumprimento do modelo de Saúde da Família, ou seja, trabalhamos com a ideia de que a participação se traduziria na ratificação da adesão dos municípios à estratégia. Em relação à segunda, levamos em consideração que os municípios pertencentes ao Projeto tenderiam a apresentar melhores indicadores de resultado ("Adequação ao Proesf”), uma vez que estariam recebendo incentivos financeiros vinculados à sua participação. Numa primeira aproximação investigativa concluímos, entretanto, que os recursos financeiros do Proesf representam uma fração pequena do financiamento da Atenção Básica. Todos os municípios contemplados pelo Projeto apresentaram para o total de recursos Proesf, no período entre 2003 (início das transferências) e 2006, um valor abaixo de $4 \%$ em relação ao total de transferências para a Atenção Básica. Por conseguinte, diferentemente do primeiro aspecto, este não se sustenta.

Com o objetivo de controlar o efeito outlier dos municípios Rio de Janeiro e São Paulo, em razão das suas singularidades sociais, econômicas e sobretudo demográficas, optou-se inicialmente por analisá-los separadamente. Entretanto, observou-se que a exclusão desses dois municípios praticamente não alterava os resultados observados em seus estratos, ainda mais considerando-se que a maioria dos indicadores utilizados está ponderada pela população sob forma de razão. Dessa forma, em nossas análises estes permanecem em seus estratos originais, e foram efetuadas observações específicas quando relevantes.

Por fim, destacamos algumas considerações:

1. Este estudo adotou o universo de municípios pertencentes aos critérios de seleção (municípios com mais de cem mil habitantes) e ao período que foram definidos, ou seja, foi desenhado em caráter censitário. Assim, os resultados encontrados foram apresentados em frequências absolutas, relativas e valores correntes e são considerados relevantes para estes conjuntos.

2. A composição dos estratos estudados é bastante heterogênea pelas próprias características do país, e controlar variáveis para fins de maior comparabilidade não nos pareceu vantajoso. Evitamos o uso de inferência estatística e deixamos assim ao leitor as observações acerca dos resultados e diferenças entre os estratos.

3. Os dados foram ordenados e os resultados apresentados em valores correntes, ou seja, sem deflacionarmos a moeda no período estudado. Para isso, consideramos que nosso estudo tem como base a comparação/proporção entre estratos, e não o desempenho individual destes ou o próprio poder de compra da moeda. Além disso, parte dos valores reflete preços administrados, e seu ajuste iria alterar os valores das transferências realmente realizadas.

\section{Resultados}

A perda de informações foi muito baixa, com destaque para Brasília, que apresentou ausência de dados para todos os indicadores estudados.

A Tabela 1 apresenta para cada ano o indicador "Participação da receita de impostos diretamente arrecadados na receita total dos municípios”, segundo região geográfica, porte populacional e participação no Proesf. Quanto maior este indicador, maior a capacidade fiscal, e espe- 
ra-se menor dependência dos municípios de outras fontes e maior autonomia política.

Quando elevada capacidade fiscal se associa a transferências financeiras elevadas (reflete capacidade de governo em captar recursos) e alto comprometimento orçamentário com o setor saúde, temos a condição considerada neste estudo de elevada sustentabilidade.

Nota-se que em todos os anos as regiões Sul e Sudeste, os municípios de alto porte e aqueles que não participam do Proesf apresentaram as maiores médias, enquanto a região Norte, os municípios de baixo porte e aqueles que participam do Proesf, as menores. Todos os grupos apontados com as maiores médias foram os únicos, juntamente com os municípios da região Sul e de médio porte populacional, que ficaram acima das médias gerais, em toda a série.

Quando avaliada a evolução no período, a região Norte, os municípios de médio, seguidos pelos de baixo porte, e os que participam do Proesf assumiram em média as maiores evoluções entre 2002 e 2006. Isto sugere uma busca por superar lacunas na oferta desses serviços. Os municípios da região Centro-Oeste, os municípios de alto porte populacional e aqueles que não participam do Proesf apresentaram as piores evoluções.
Quanto aos desempenhos individuais dos municípios, as tendências observadas para a região Norte se mantêm, apresentando a maior proporção de municípios com evolução positiva, juntamente com os de médio e alto portes e aqueles que participam do Projeto.

$\mathrm{O}$ indicador "Percentual da receita própria aplicada na saúde (PRPAS)" e o indicador "Adequação à EC 29" demonstram, respectivamente, os percentuais aplicados e a diferença em relação a proposto pela Emenda Constitucional no 29/ 00 , tomada como parâmetro neste estudo antes de sua regulamentação.

Nesse sentido, analisando os municípios segundo as regiões, o porte populacional e a participação no Proesf, percebe-se a partir da Tabela 2 que em todo o período os municípios da região Sudeste, aqueles de médio e baixo portes e os que não participam do Proesf (exceto 2001) aplicaram em média mais de sua receita em saúde quando comparados com os demais. Por sua vez, os municípios das regiões Norte e Nordeste, aqueles de alto porte e os que participam do Proesf apresentaram as menores médias em todos os anos observados. Aqueles que apresentaram as maiores médias também foram os únicos que ficaram acima das médias gerais.

Tabela 1. Variação do percentual médio de participação da receita de impostos na receita total do município segundo região, porte populacional e participação no Proesf e frequência absoluta da classificação dos municípios segundo sua variação individual - 2002/2006 (N=239).

\begin{tabular}{|c|c|c|c|c|c|c|c|c|c|}
\hline & \multicolumn{5}{|c|}{ Variação da participação } & \multicolumn{4}{|c|}{ Tipo de evolução (frequência absoluta) } \\
\hline & 2002 & 2003 & 2004 & 2005 & 2006 & Negativa & Conservadora & Positiva & Total \\
\hline \multicolumn{10}{|l|}{ Região } \\
\hline $\mathrm{N}$ & 9,95 & 10,48 & 10,44 & 10,69 & 11,04 & 5 & 1 & 9 & 15 \\
\hline $\mathrm{NE}$ & 11,92 & 11,72 & 11,38 & 11,67 & 12,03 & 24 & 6 & 18 & 48 \\
\hline SE & 20,98 & 21,62 & 21,69 & 21,56 & 21,32 & 54 & 35 & 33 & 122 \\
\hline S & 19,26 & 19,63 & 20,13 & 19,92 & 20,15 & 18 & 12 & 11 & 41 \\
\hline $\mathrm{CO}$ & 17,41 & 18,47 & 16,94 & 15,47 & 16,29 & 6 & 2 & 3 & 11 \\
\hline Total & 17,98 & 18,42 & 18,40 & 18,29 & 18,34 & 107 & 56 & 74 & $237^{*}$ \\
\hline \multicolumn{10}{|c|}{ Porte populacional } \\
\hline Baixo & 16,61 & 17,10 & 17,09 & 16,86 & 16,90 & 93 & 49 & 60 & 202 \\
\hline Médio & 24,43 & 24,80 & 24,78 & 25,20 & 25,21 & 12 & 6 & 12 & 30 \\
\hline Alto & 34,88 & 33,50 & 32,98 & 34,85 & 35,45 & 2 & 1 & 2 & 5 \\
\hline Total & 17,98 & 18,42 & 18,40 & 18,29 & 18,34 & 107 & 56 & 74 & $237^{*}$ \\
\hline \multicolumn{10}{|c|}{ Participação no Proesf } \\
\hline Sim & 17,12 & 17,55 & 17,39 & 17,36 & 17,57 & 87 & 41 & 62 & 190 \\
\hline Não & 21,48 & 21,94 & 22,46 & 21,99 & 21,38 & 20 & 15 & 12 & 47 \\
\hline Total & 17,98 & 18,42 & 18,40 & 18,29 & 18,34 & 107 & 56 & 74 & $237^{*}$ \\
\hline
\end{tabular}

Fonte: Elaboração própria a partir do Siops.

* Missing: 02 (01 exclusão por falta de dados para o ano 2002; 01 exclusão por falta de dados para os anos 2002 e 2006). 
Analisando a evolução do percentual médio da receita própria aplicada em saúde entre 2000 e 2006, evidenciaram-se os maiores aumentos para os municípios da região Nordeste, seguida da Norte, municípios com porte populacional alto e para aqueles que participam do Proesf. Os municípios da região Sudeste, os municípios de médio porte populacional e aqueles que não participam do Proesf apresentaram as menores evoluções. Isto é consistente com o observado para o indicador anterior ("Participação da receita de impostos diretamente arrecadados na receita total dos municípios”).

Analisando individualmente estes municípios, as maiores proporções de casos de evolução positiva ficaram por conta dos municípios da região Norte, dos municípios de alto porte e dos municípios que participam do Proesf.

A variação ano a ano do indicador "Adequação à EC 29", evidenciada na Tabela 3, segue a mesma tendência de variação do indicador "PRPAS", uma vez que maiores percentuais de aplicação refletem maiores disponibilidades ao gasto para além do proposto pela Emenda Constitucional $n^{\circ} 29 / 00$.

Nota-se que, em média, todos os municípios, seja pela região geográfica, seja pelo porte popu- lacional ou pela participação no Proesf, apresentaram uma diferença positiva, ou seja, gastaram em saúde em todos os anos estudados mais do que o proposto pela $\mathrm{EC} \mathrm{n}^{\circ} 29 / 00$. Isto reflete a importância progressiva das políticas de saúde nos orçamentos públicos. Quando observada esta variação por dentro dos estratos, percebemse os poucos casos de evolução negativa em todas as estratificações. Esta é uma característica conhecida das regiões brasileiras onde existem variações internas relevantes.

Destacamos também que, com exceção da região Nordeste, para todos os casos esta disponibilidade para realizar despesas além do proposto pela $E C n^{\circ} 29 / 00$ tende a diminuir. Todavia, é preciso levar em consideração os percentuais progressivos de vinculação da receita segundo a EC n ${ }^{\circ} 29 / 00: 7 \%$ (2000); 8,6\% (2001); 10,2\% (2002); 11,8\% (2003) e 15\% (a partir de 2004).

Os indicadores "DPSPC" e "MEGPC" foram aplicados em duas formas: considerando a fórmula original (15\% da receita vinculável) e, para efeito de comparação, considerando a evolução dos percentuais de vinculação de receitas segundo a Emenda Constitucional no 29/00. Como na segunda ótica não houve modificações significativas em relação ao observado na primeira, op-

Tabela 2. Variação do percentual médio de receita própria aplicada em saúde segundo região, porte populacional e participação no Proesf e frequência da classificação dos municípios segundo sua evolução individual - 2000/2006 $(\mathrm{N}=239)$.

\begin{tabular}{|c|c|c|c|c|c|c|c|c|c|c|c|}
\hline & \multicolumn{7}{|c|}{ Variação da participação } & \multicolumn{4}{|c|}{$\begin{array}{c}\text { Tipo de evolução } \\
\text { (frequência absoluta) }\end{array}$} \\
\hline & 2000 & 2001 & 2002 & 2003 & 2004 & 2005 & 2006 & Negativa & Estável & Positiva & Total \\
\hline \multicolumn{12}{|l|}{ Região } \\
\hline $\mathrm{N}$ & 10,34 & 13,05 & 14,05 & 15,89 & 16,49 & 16,50 & 18,19 & 0 & 0 & 12 & 12 \\
\hline $\mathrm{NE}$ & 9,33 & 13,19 & 13,87 & 14,78 & 16,08 & 17,42 & 18,37 & 3 & 3 & 39 & 45 \\
\hline SE & 17,45 & 17,31 & 18,69 & 20,01 & 20,15 & 21,29 & 22,45 & 22 & 11 & 85 & 118 \\
\hline$S$ & 13,36 & 15,54 & 15,71 & 16,46 & 17,29 & 18,52 & 19,25 & 4 & 3 & 34 & 41 \\
\hline $\mathrm{CO}$ & 13,25 & 14,58 & 16,02 & 13,77 & 17,39 & 18,21 & 20,38 & 3 & 0 & 9 & 12 \\
\hline Total & 14,52 & 15,76 & 16,77 & 17,79 & 18,47 & 19,57 & 20,70 & 32 & 17 & 179 & $228^{*}$ \\
\hline \multicolumn{12}{|c|}{ Porte populacional } \\
\hline Baixo & 14,37 & 15,70 & 16,83 & 17,83 & 18,53 & 19,58 & 20,79 & 23 & 16 & 155 & 194 \\
\hline Médio & 16,10 & 16,76 & 16,46 & 17,94 & 18,35 & 19,68 & 20,68 & 9 & 1 & 19 & 29 \\
\hline Alto & 11,06 & 12,06 & 16,02 & 15,03 & 16,72 & 18,48 & 17,49 & 0 & 0 & 5 & 5 \\
\hline Total & 14,52 & 15,76 & 16,77 & 17,79 & 18,47 & 19,57 & 20,70 & 32 & 17 & 179 & $228^{*}$ \\
\hline \multicolumn{12}{|c|}{ Participação no Proesf } \\
\hline Sim & 14,16 & 15,58 & 16,39 & 17,55 & 18,30 & 19,43 & 20,64 & 23 & 14 & 145 & 182 \\
\hline Não & 15,93 & 16,50 & 18,31 & 18,75 & 19,17 & 20,16 & 20,95 & 9 & 3 & 34 & 46 \\
\hline Total & 14,52 & 15,76 & 16,77 & 17,79 & 18,47 & 19,57 & 20,70 & 32 & 17 & 179 & $228^{*}$ \\
\hline
\end{tabular}

Fonte: Elaboração própria a partir do Siops.

"Missing: 11 ( 10 exclusões por falta de dados para o ano 2002; 01 exclusão por falta de dados para os anos 2002 e 2006). 
tou-se por não apresentá-la em nome da concisão. Estes dois indicadores devem ser interpretados de modo combinado.

Os maiores valores médios para o indicador "DPSPC" (Tabela 4) foram encontrados, para toda a série, nos municípios da região Sudeste, nos municípios de médio e alto portes populacionais e naqueles que participam do Proesf, ao passo que os municípios da região Norte, municípios de baixo porte populacional e aqueles que não participam do Proesf apresentaram os menores valores.

Nota-se que, segundo o porte populacional e a participação no Proesf, aqueles que apresentaram as maiores médias foram os únicos que para todo o período ficaram acima da média geral. Quanto às regiões geográficas, percebe-se que nos anos 2000, 2001 e 2002 a região Sudeste era a única a figurar acima da média geral, e em 2005 e 2006, mais duas regiões se colocaram também nessa situação: Nordeste e Centro-Oeste.

O indicador MEGPC (Tabela 4), que compara o valor apurado no indicador DPSPC com o atual gasto com saúde, pode ser interpretado, segundo Pereira et al. ${ }^{1}$, de duas formas. No primeiro modo de ler, os municípios mais bem posicionados são aqueles que têm menor margem de expansão de gastos, ou seja, que já gastam com saúde além de sua despesa potencial (indicador “DPSPC"). Por esse prisma, os municípios mais bem posicionados para toda a série, em média, são os que pertencem à região Sudeste, municípios de médio porte e aqueles que não participam do Proesf.

O segundo modo de interpretar o indicador é o inverso do anterior, ou seja, o município que apresentar maior margem de expansão do gasto com saúde é o que mais poderá incorporar novos investimentos, porque ainda gasta com saúde um valor aquém do seu potencial. Nessa ótica, os municípios das regiões Norte e Nordeste, os municípios de alto porte e aqueles que participam do Proesf ficaram, em média, com as melhores posições.

Embora haja possibilidade de diferentes interpretações, consideramos em nosso estudo que maior gasto em saúde favorece a maior sustentabilidade dos programas.

Quando as médias das regiões são comparadas com a média geral, ganha destaque a região Sudeste, única a apresentar valores inferiores a esta para toda a série. Os municípios de médio porte, com exceção do ano 2004, e aqueles que não participam do Proesf apresentaram para todo o período valores abaixo das médias gerais.

No que se relaciona à evolução do indicador "DPSPC", tomando como perspectiva a diferença absoluta dos valores encontrados em 2006 e 2002, concluímos que os municípios da região Nordeste, municípios de alto porte populacional e os municípios que participam do Proesf fica-

Tabela 3. Variação do indicador “Adequação à EC 29" segundo o porte populacional - 2000 a 2006 $(\mathrm{N}=239)$.

\begin{tabular}{lrrrrrrr}
\hline & \multicolumn{7}{c}{ Variação da diferença } \\
\cline { 2 - 7 } & $\mathbf{2 0 0 0}$ & $\mathbf{2 0 0 1}$ & $\mathbf{2 0 0 2}$ & $\mathbf{2 0 0 3}$ & $\mathbf{2 0 0 4}$ & $\mathbf{2 0 0 5}$ & $\mathbf{2 0 0 6}$ \\
\hline Região & & & & & & & \\
N & 3,34 & 4,45 & 3,85 & 4,09 & 1,49 & 1,50 & $-3,19$ \\
NE & 2,33 & 4,59 & 3,67 & 2,98 & 1,08 & 2,42 & 3,37 \\
SE & 10,45 & 8,71 & 8,49 & 8,21 & 5,15 & 6,29 & 7,45 \\
S & 6,36 & 6,94 & 5,51 & 4,66 & 2,29 & 3,52 & 4,25 \\
CO & 6,25 & 5,98 & 5,82 & 1,97 & 2,39 & 3,21 & 5,38 \\
Total & 7,52 & 7,16 & 6,57 & 5,99 & 3,47 & 4,57 & 5,70 \\
Porte populacional & & & & & & & \\
$\quad$ Baixo & 7,37 & 7,10 & 6,63 & 6,03 & 3,53 & 4,58 & 5,79 \\
Médio & 9,10 & 8,16 & 6,26 & 6,14 & 3,35 & 4,68 & 5,68 \\
Alto & 4,06 & 3,46 & 5,82 & 3,23 & 1,72 & 3,48 & 2,49 \\
$\quad$ Total & 7,52 & 7,16 & 6,57 & 5,99 & 3,47 & 4,57 & 5,70 \\
Participação no Proesf & & & & & & & \\
Sim & 7,16 & 6,98 & 6,19 & 5,75 & 3,30 & 4,43 & 5,64 \\
$\quad$ Não & 8,93 & 7,90 & 8,11 & 6,95 & 4,17 & 5,16 & 5,95 \\
$\quad$ Total & 7,52 & 7,16 & 6,57 & 5,99 & 3,47 & 4,57 & 5,70 \\
\hline
\end{tabular}

Fonte: Elaboração própria a partir do Siops. 
ram com melhores evoluções, ou seja, foram aqueles que entre 2000 e 2006 mais agregaram potencial de despesa com ações e serviços de saúde, ao passo que os municípios da região Norte, municípios de baixo e médio portes populacionais e aqueles que não participam do Proesf foram os que menos evoluíram no período.

Quanto ao indicador "Adequação ao Proesf”, observando-se a Tabela 5, percebe-se que os municípios da região Nordeste, seguidos dos da Norte, os de alto porte populacional e aqueles que participam do Proesf são os que apresentaram maiores médias de cobertura da ESF, ou seja, são os municípios que estão mais próximos das metas de pactuadas pelo Proesf, que tomam como referência o porte populacional dos municípios.

Podemos adiantar que esse parâmetro de alguma forma justifica os achados para o porte populacional, pois quanto menor o porte, maior é a meta pactuada de cobertura.

Tabela 4. Variação dos indicadores "Despesa potencial em saúde per capita (DPSPC)" e "Margem de expansão do gasto per capita (MEGPC)" segundo região, porte populacional e participação no Proesf 2000/2006 ( $\mathrm{N}=239)$.

\begin{tabular}{|c|c|c|c|c|c|c|c|}
\hline & \multicolumn{7}{|c|}{ Despesa potencial em saúde per capita (variação em reais) } \\
\hline & 2000 & 2001 & 2002 & 2003 & 2004 & 2005 & 2006 \\
\hline \multicolumn{8}{|l|}{ Região } \\
\hline $\mathrm{N}$ & 69,40 & 85,91 & 99,00 & 112,68 & 128,46 & 138,31 & 156,32 \\
\hline $\mathrm{NE}$ & 88,57 & 103,60 & 121,05 & 132,63 & 163,39 & 176,71 & 200,16 \\
\hline SE & 111,09 & 121,62 & 132,59 & 146,94 & 169,79 & 181,99 & 201,90 \\
\hline S & 96,49 & 108,62 & 120,48 & 135,55 & 159,84 & 172,37 & 190,55 \\
\hline $\mathrm{CO}$ & 88,56 & 103,98 & 110,98 & 141,20 & 157,95 & 182,62 & 198,44 \\
\hline Total & 100,22 & 112,61 & 124,97 & 139,64 & 163,58 & 176,55 & 196,55 \\
\hline \multicolumn{8}{|c|}{ Porte populacional } \\
\hline Baixo & 96,08 & 108,18 & 120,68 & 135,21 & 158,17 & 171,19 & 190,84 \\
\hline Médio & 124,48 & 138,26 & 149,59 & 163,87 & 193,52 & 208,08 & 227,06 \\
\hline Alto & 122,02 & 138,58 & 151,32 & 174,08 & 203,99 & 204,96 & 245,01 \\
\hline Total & 100,22 & 112,61 & 124,97 & 139,64 & 163,58 & 176,55 & 196,55 \\
\hline \multicolumn{8}{|c|}{ Participação no Proesf } \\
\hline Sim & 102,33 & 115,45 & 128,73 & 144,14 & 170,23 & 183,27 & 204,29 \\
\hline Não & 91,94 & 101,38 & 110,09 & 121,82 & 137,27 & 149,94 & 165,91 \\
\hline \multirow[t]{3}{*}{ Total } & 100,22 & 112,61 & 124,97 & 139,64 & 163,58 & 176,55 & 196,55 \\
\hline & \multicolumn{7}{|c|}{ Margem de expansão do gasto per capita (variação em reais) } \\
\hline & 2000 & 2001 & 2002 & 2003 & 2004 & 2005 & 2006 \\
\hline \multicolumn{8}{|l|}{ Região } \\
\hline $\mathrm{N}$ & 9,42 & 3,53 & 0,36 & $-0,90$ & $-4,53$ & $-1,04$ & $-7,96$ \\
\hline $\mathrm{NE}$ & 14,34 & 5,64 & 3,72 & 0,47 & $-0,66$ & $-2,84$ & $-10,69$ \\
\hline SE & $-5,49$ & $-7,78$ & $-14,97$ & $-23,05$ & $-30,43$ & $-33,29$ & $-43,19$ \\
\hline$S$ & 6,02 & $-0,72$ & $-2,28$ & $-5,08$ & $-9,95$ & $-15,27$ & $-23,62$ \\
\hline $\mathrm{CO}$ & 4,04 & 0,61 & $-3,64$ & 4,39 & $-15,55$ & $-11,90$ & $-22,52$ \\
\hline Total & 1,94 & $-2,72$ & $-7,48$ & $-12,43$ & $-18,52$ & $-20,93$ & $-30,00$ \\
\hline \multicolumn{8}{|c|}{ Porte populacional } \\
\hline Baixo & 2,70 & $-2,25$ & $-7,35$ & $-12,27$ & $-19,06$ & $-20,74$ & $-29,97$ \\
\hline Médio & $-5,00$ & $-8,21$ & $-8,60$ & $-15,69$ & $-16,44$ & $-22,72$ & $-33,37$ \\
\hline Alto & 13,18 & 10,97 & $-5,72$ & 0,65 & $-8,81$ & $-18,08$ & $-11,25$ \\
\hline Total & 1,94 & $-2,72$ & $-7,48$ & $-12,43$ & $-18,52$ & $-20,93$ & $-30,00$ \\
\hline \multicolumn{8}{|c|}{ Participação no Proesf } \\
\hline Sim & 2,63 & $-2,54$ & $-6,01$ & $-11,13$ & $-16,81$ & $-19,33$ & $-28,91$ \\
\hline Não & $-0,74$ & $-3,46$ & $-13,30$ & $-17,59$ & $-25,26$ & $-27,30$ & $-34,33$ \\
\hline Total & 1,94 & $-2,72$ & $-7,48$ & $-12,43$ & $-18,52$ & $-20,93$ & $-30,00$ \\
\hline
\end{tabular}

Fonte: Elaboração própria a partir do Siops. 
Os municípios que apresentaram as médias mais baixas, ou seja, estão mais distantes das metas, são os das regiões Sudeste e Sul, os de baixo porte populacional (maior meta) e aqueles que não participam do Proesf.

Os grupos apontados com as maiores médias foram os únicos, juntamente com os municípios de médio porte populacional, que ficaram acima das médias gerais, em todos os anos.

Nota-se que, em média, todos os municípios, seja pela região geográfica, seja pelo porte populacional ou pela participação no Proesf, apresentam uma diferença negativa, ou seja, demonstraram uma cobertura média da ESF em todos os anos estudados menor do que o Proesf propõe.

Destaca-se a observação de que os municípios da região Nordeste e os que participam do Proesf, além de apresentarem as maiores médias (menores diferenças) em todos os anos, são os que mais evoluíram no período, considerando a diferença absoluta em pontos percentuais entre os anos 2006 e 2003. Por sua vez, os municípios de alto porte populacional, que apresentaram maiores médias em todos os anos, foram os que menos evoluíram.

Estes resultados refletem de alguma forma o padrão econômico e de urbanização daqueles

Tabela 5. Variação do indicador "Adequação ao Proesf" (diferença entre a cobertura da ESF e a meta pactuada) segundo região, porte populacional e participação no Proesf - 2003/2006 (N=239).

\begin{tabular}{lrrrr}
\hline & \multicolumn{4}{c}{ Variação da diferença } \\
\cline { 2 - 5 } & $\mathbf{2 0 0 3}$ & $\mathbf{2 0 0 4}$ & $\mathbf{2 0 0 5}$ & $\mathbf{2 0 0 6}$ \\
\hline Região & & & & \\
N & $-38,01$ & $-33,90$ & $-32,18$ & $-27,93$ \\
NE & $-17,29$ & $-11,77$ & $-11,19$ & $-6,30$ \\
SE & $-47,64$ & $-44,07$ & $-41,86$ & $-38,92$ \\
S & $-50,87$ & $-44,35$ & $-41,74$ & $-38,37$ \\
CO & $-41,74$ & $-39,27$ & $-38,51$ & $-36,09$ \\
Total & $-40,96$ & $-36,51$ & $-34,68$ & $-31,21$ \\
Porte populacional & & & & \\
Baixo & $-43,23$ & $-38,70$ & $-36,97$ & $-33,43$ \\
Médio & $-30,28$ & $-25,18$ & $-22,75$ & $-19,26$ \\
Alto & $-18,16$ & $-19,35$ & $-17,09$ & $-15,72$ \\
Total & $-40,96$ & $-36,51$ & $-34,68$ & $-31,21$ \\
Participação no Proesf & & & & \\
Sim & $-37,34$ & $-32,34$ & $-30,26$ & $-26,47$ \\
Não & $-56,88$ & $-54,84$ & $-54,09$ & $-52,00$ \\
Total & $-40,96$ & $-36,51$ & $-34,68$ & $-31,21$ \\
\hline
\end{tabular}

Fonte: Elaboração própria a partir do Datasus. municípios que reconhecidamente estão mais aderidos ao modelo de Saúde da Família.

O Quadro 2 sintetiza os principais resultados encontrados para os valores médios e a evolução tomando como referência os anos extremos.

Em resumo, há uma tendência de os municípios das regiões Sul e Sudeste se apresentarem de modo mais sustentável e contínuo: as mais elevadas médias para os indicadores "Participação da receita de impostos na receita total do município (PRIRT)", "Percentual da receita própria aplicada na saúde (PRPAS)", “Adequação à EC 29” e "Despesa potencial em saúde per capita (DPSPC)" são consistentes com a percepção geral de maior poder econômico destas regiões no país. Isto deve ser combinado ao conhecido fato de estas regiões terem também maior cobertura de planos privados de saúde. Logo, os recursos públicos são mais liberados para gastos com a população dependente do SUS.

A variável porte populacional teve que ser analisada com mais cuidado. Era esperado que os resultados encontrados para ela acompanhassem a mesma tendência observada para a variável região geográfica. Percebemos, entretanto, que tal situação não foi a observada, acontecendo uma oscilação de resultados entre os indicadores de sustentabilidade econômico-financeira. Uma possível explicação é a estrutura de comparação que se deu no universo dos municípios estudados, dado que a distribuição dos municípios nas três classificações possíveis é muito desigual. Assim, a variável porte populacional ficou comprometida como explicação, pois não há uma total associação entre aqueles categorizados quanto ao porte populacional e à região. Para a região Sudeste, por exemplo, do conjunto dos seus 222 municípios, apenas três $(2,5 \%)$ estavam na categoria "alto porte", e $105(86,1 \%)$ estavam na categoria "baixo porte". Por sua vez, para a região Nordeste, do total dos seus 48 municípios, dois $(4,2 \%)$ pertenciam à categoria "alto porte" e $37(77,1 \%)$ à categoria "baixo porte”. No entanto, o mais plausível é que o efeito porte tenha sido atenuado pelo próprio universo de municípios estudados. Em nosso entendimento, o grupo de municípios que normalmente discriminariam seriam aqueles com menos de cem mil habitantes, e estes não foram objetos de análise neste estudo.

A participação no Proesf se mostra uma variável que pouco discriminou na análise. Os dados sugerem, todavia, que os municípios participantes estariam entre os mais vulneráveis, apresentando as menores médias para os indicadores "Participação da receita de impostos na recei- 
Quadro 2. Principais resultados referentes aos valores médios e à evolução no período estudado.

\begin{tabular}{|l|l|l|l|l|}
\hline \multirow{2}{*}{\multicolumn{1}{|c|}{ Indicadores }} & \multicolumn{1}{c|}{ Maiores } & \multicolumn{1}{c|}{ Menores } & \multicolumn{1}{c|}{ Maiores } & \multicolumn{1}{c|}{ Menores } \\
\cline { 2 - 5 } & \multicolumn{1}{c|}{$\begin{array}{l}\text { Morãa no período estudado } \\
\text { Participação da receita } \\
\text { de impostos na receita } \\
\text { total do município } \\
\text { (PRIRT) }\end{array}$} & $\begin{array}{l}\text { Sudeste } \\
\text { Alto porte } \\
\text { Não Proesf } \\
\text { Sim Proesf }\end{array}$ & $\begin{array}{l}\text { Norte } \\
\text { Médio porte } \\
\text { Sim Proesf }\end{array}$ & $\begin{array}{l}\text { Centro-Oeste } \\
\text { Alto porte } \\
\text { Não Proesf }\end{array}$ \\
\hline $\begin{array}{l}\text { Percentual da receita } \\
\text { própria aplicada na } \\
\text { saúde (PRPAS) }\end{array}$ & $\begin{array}{l}\text { Sudeste } \\
\text { Médio e baixo portes } \\
\text { Não Proesf }\end{array}$ & $\begin{array}{l}\text { Norte e Nordeste } \\
\text { Alto porte } \\
\text { Sim Proesf }\end{array}$ & $\begin{array}{l}\text { Nordeste } \\
\text { Alto porte } \\
\text { Sim Proesf }\end{array}$ & $\begin{array}{l}\text { Sudeste } \\
\text { Médio porte } \\
\text { Não Proesf }\end{array}$ \\
\hline $\begin{array}{l}\text { Adequação à EC } 29 \\
\text { Sudeste } \\
\text { Médio e baixo portes } \\
\text { Não Proesf }\end{array}$ & $\begin{array}{l}\text { Norte e Nordeste } \\
\text { Alto porte } \\
\text { Sim Proesf }\end{array}$ & $\begin{array}{l}\text { Nordeste } \\
\text { Baixo porte } \\
\text { Sim Proesf }\end{array}$ & $\begin{array}{l}\text { Sul } \\
\text { Alto porte } \\
\text { Não Proesf }\end{array}$ \\
\hline $\begin{array}{l}\text { Despesa potencial em } \\
\text { saúde per capita } \\
\text { (DPSPC) }\end{array}$ & $\begin{array}{l}\text { Sudeste } \\
\text { Médio e alto portes } \\
\text { Sim Proesf }\end{array}$ & $\begin{array}{l}\text { Norte } \\
\text { Baixo porte } \\
\text { Não Proesf }\end{array}$ & $\begin{array}{l}\text { Nordeste } \\
\text { Alto porte } \\
\text { Sim Proesf }\end{array}$ & $\begin{array}{l}\text { Norte } \\
\text { Baixo porte } \\
\text { Não Proesf }\end{array}$ \\
\hline $\begin{array}{l}\text { Margem de expansão } \\
\text { do gasto per capita } \\
\text { (MEGPC) }\end{array}$ & $\begin{array}{l}\text { Norte e Nordeste } \\
\text { Alto porte } \\
\text { Sim Proesf }\end{array}$ & $\begin{array}{l}\text { Sudeste } \\
\text { Médio porte } \\
\text { Não Proesf }\end{array}$ & $\begin{array}{l}\text { Norte } \\
\text { Alto porte } \\
\text { Sim Proesf }\end{array}$ & $\begin{array}{l}\text { Sudeste } \\
\text { Baixo porte } \\
\text { Não Proesf }\end{array}$ \\
\hline $\begin{array}{l}\text { Adequação ao Proesf } \\
\text { Nordeste } \\
\text { Alto porte } \\
\text { Sim Proesf }\end{array}$ & $\begin{array}{l}\text { Sudeste e Sul } \\
\text { Baixo porte } \\
\text { Não Proesf }\end{array}$ & $\begin{array}{l}\text { Nordeste } \\
\text { Médio porte } \\
\text { Sim Proesf }\end{array}$ & $\begin{array}{l}\text { Centro-Oeste } \\
\text { Alto porte } \\
\text { Não Proesf }\end{array}$ \\
\hline
\end{tabular}

Fonte: Elaboração própria.

ta total do município", "Percentual da receita própria aplicada na saúde" e "Adequação à EC 29". Para o indicador "Despesa potencial em saúde", apesar de os participantes apresentarem as maiores médias, o componente receita de impostos e transferências constitucionais e legais é o mais baixo, sendo compensado pelas transferências intergovernamentais para a saúde por habitante. Isto ratifica a fragilidade econômico-financeira deles quando comparados aos demais. Levando em consideração, entretanto, que os municípios aderidos ao Projeto são aqueles com melhores valores médios para o indicador de resultado "Adequação ao Proesf", entende-se que a participação poderia ser uma oportunidade de compensação ante sua vulnerabilidade. Podemos sugerir ainda que o fato de os não participantes terem maior capacidade fiscal signifique menos dependência em buscar tais recursos.

Analisando os municípios Rio de Janeiro e São Paulo separadamente dos seus estratos originais (região Sudeste, alto pote populacional e participação no Proesf afirmativa), podemos destacar alguns achados importantes.

Para o indicador "Participação da receita de impostos diretamente arrecadados na receita to- tal dos municípios", os dois municípios apresentaram médias em todo o período maiores que as médias de participação dos demais municípios agrupados por região, porte e participação no Proesf. As médias são, inclusive, maiores que o dobro da média geral de todos os municípios.

Já para os indicadores "Percentual da receita própria aplicada na saúde" e "Adequação à EC 29”, os municípios Rio de Janeiro e São Paulo, na mesma perspectiva de análise, apresentaram (com exceção de São Paulo para o ano 2002) valores abaixo das médias gerais, ou seja, aplicaram menos de sua receita no setor saúde, quando comparados com a média de todos os municípios.

No que diz respeito aos indicadores "Despesa potencial em saúde per capita" e "Margem de expansão do gasto per capita”, percebemos que, para o primeiro, Rio de Janeiro apresentou valores nominais para gastos em saúde por habitante em todos os anos estudados maiores que os valores médios dos demais municípios agrupados por região, porte populacional e participação no Proesf. Podemos destacar também que Rio de Janeiro, diferentemente de São Paulo, apresentou valores nominais acima da média geral em toda a série. Para o indicador "MEGPC", os 
dois atingiram valores nominais acima da média geral (com exceção dos anos 2002 e 2003).

Para o último indicador ("Adequação ao Proesf”), Rio de Janeiro e São Paulo tiveram valores acima das médias gerais, com destaque para São Paulo, que deteve os maiores valores em todos os anos estudados quando comparados com os valores médios dos demais municípios agrupados por região, porte populacional e participação no Proesf.

É importante destacarmos que para todos os indicadores, mesmo com a exclusão de Rio de Janeiro e São Paulo dos seus estratos originais, as posições dos grupos, no que se refere às maiores e menores médias, não se alteram em relação aos achados iniciais já apresentados como resultados.

\section{Considerações finais}

O processo investigativo permitiu-nos concluir que a variável região geográfica foi a que melhor explicou os fenômenos observados. Nesse sentido, pertencer à região Sudeste significou ter as maiores médias para a "Participação da receita de impostos na receita total do município" e, provavelmente em razão dessa maior capacidade fiscal, maiores médias para "Percentual da receita própria aplicada na saúde”, portanto, maiores médias para "Adequação à EC 29". Ao se cotejarem os resultados obtidos, tem-se que considerar que essa é a região do país que mais acumula municípios economicamente desenvolvidos e que concentra a maior parte do produto interno bruto (PIB) nacional, o que justificaria os achados apresentados, assim como o fato de o Sudeste também apresentar as maiores médias para o indicador "Despesa potencial em saúde per capita", uma vez que este está diretamente associado à receita de impostos e transferências constitucionais e legais per capita.

Apesar de o indicador "Margem de expansão do gasto per capita" ser diretamente proporcional ao indicador "Despesa potencial em saúde per capita”, a região Sudeste apresenta o menor valor médio para esse indicador, o que se explica pelo fato de ser a região que apresenta a maior despesa total com saúde por habitante.

Para o indicador "Adequação ao Proesf”, a região Sudeste destoa em relação aos achados anteriores, estando em média mais afastada das metas pactuadas pelo Projeto, o que pode indicar que esses municípios estariam menos aderidos à ESF. Uma possível explicação seria a presença nessa região de grandes capitais dotadas de uma rede de serviços de saúde diversificada e complexa, que pode estar competindo com a consolidação e estruturação da Estratégia Saúde da Família.

$\mathrm{Na}$ outra vertente, as regiões Norte e Nordeste foram aquelas que apresentam as menores médias para os indicadores de sustentabilidade econômico-financeira, com exceção do indicador "Margem de expansão do gasto per capita", para o qual tiveram as maiores médias, uma vez que são as regiões com as menores despesas totais com saúde por habitante. Por sua vez, a região Nordeste foi a que deteve as maiores médias para o indicador "Adequação ao Proesf". Cabe também destacar que apesar de essas duas regiões serem as que em média apresentaram municípios mais vulneráveis econômica e financeiramente, foram as que mais evoluíram no período para todos os indicadores estudados, o que poderia também levar a uma condição de vulnerabilidade fiscal ou de cortes orçamentários em outras políticas essenciais, como educação e saneamento.

Assim como para a variável região, para a participação no Proesf os municípios mais vulneráveis foram aqueles que mais evoluíram no período, o que agravaria ainda mais a sua vulnerabilidade fiscal pelo esforço em melhorar indicadores de cobertura.

Para o indicador "Adequação ao Proesf", os municípios de alto porte populacional são que estão mais próximos das metas de cobertura pactuadas pelo Proesf, enquanto os de baixo porte estão mais distantes. Esses resultados não trazem surpresa, levando em consideração que, como bem observado nos resultados, as metas pactuadas são inversamente proporcionais ao porte populacional dos municípios.

Dessa forma, apesar de em nossas análises termos de fato constatado que na prática os municípios de baixo porte apresentavam as maiores médias de cobertura da ESF, estas não são proporcionais às metas definidas para eles, que, por serem maiores, tornam as médias do indicador "Adequação ao Proesf" menores.

Finalmente, a propósito das considerações discutidas ao longo deste artigo, observamos que a expansão e a sustentabilidade da ESF constituem um processo político que vem se tornando cada vez mais forte, uma vez que tanto o comprometimento orçamentário quanto as médias de cobertura relacionados à estratégia estão se expandindo.

Mencionamos ainda que as comparações por estratos aqui apresentadas tornaram-se de alguma forma problemática devido à desigualdade dentro dessas regiões. No entanto, como mostra 
o estudo, essa agregação permitiu visualizar importantes diferenças: os resultados refletem padrões de desenvolvimento econômico e tipos de urbanização.

\section{Colaboradores}

GZ Portela e JM Ribeiro participaram da concepção geral, análise de dados, discussão dos resultados e redação final do artigo.

\section{Referências}

1. Pereira ATS, Campelo ACFS, Cunha FS, Noronha J, Cordeiro H, Dain S, Pereira TR. A sustentabilidade econômico-financeira no Proesf em municípios do Amapá, Maranhão, Pará e Tocantins. Cien Saude Colet 2006; 11(3):607-620.

2. Marques RM, Mendes A. A dimensão do financiamento da Atenção Básica e do PSF no contexto da saúde SUS. In: Sousa MF. Os sinais vermelhos do PSF. São Paulo: Hucitec; 2002. p. 71-104.

3. Marques RM, Mendes A. A política de incentivos do Ministério da Saúde para a atenção básica: uma ameaça à autonomia dos gestores municipais e ao princípio da integralidade? Cad Saude Publica 2002; 18(Supl.):163-171.

4. Marques RM, Mendes A. Atenção Básica e Programa Saúde da Família (PSF): novos rumos para a política de saúde e seu financiamento? Cien Saude Colet 2003; 8(2):403-415.

5. Marques RM, Ugá MAD. Financiamento do SUS: trajetória, contexto e constrangimentos. In: Lima NT, Gerschman S, Edler FC, Suárez JM. Saúde e democracia: história e perspectivas do SUS. Rio de Janeiro: Fiocruz; 2005. p. 193-233.

6. Melamed C, Costa NR. Inovações no financiamento federal à Atenção Básica. Cien Saude Colet 2003; 8(2):393-401.

7. Vianna AL, Dal Poz MR. A Reforma Sanitária do Sistema de Saúde no Brasil e Programa de Saúde da Família. Physis - Rev Saúde Col 1998; 8(2):11-48.

8. Brasil. Portaria no 1.099 , de 11 de julho de 2003. Aprova e habilita os municípios para participarem do Projeto de Expansão e Consolidação do Saúde da Família-Proesf. Diário Oficial da União 2003; 14 jul. [acessado 2008 jun]. Disponível em: http:// dtr2002.saude.gov.br/proesf/

9. Brasil. Portaria no 1.945 , de 10 de outubro de 2003. Aprova e habilita os municípios para participarem do Projeto de Expansão e Consolidação do Saúde da Família-Proesf. Diário Oficial da União 2003; 13 out. [acessado 2008 jun]. Disponível em: http:// dtr2002.saude.gov.br/proesf/ 
10. Brasil. Portaria no 2.216, de 20 de novembro de 2003. Aprova e habilita os municípios para participarem do Projeto de Expansão e Consolidação do Saúde da Família- Proesf. Diário Oficial da União 2003; 24 nov. [acessado 2008 jun]. Disponível em: http://dtr2002.saude.gov.br/proesf/

11. Brasil. Portaria no 744, de 22 de abril de 2004. Aprova e habilita os municípios para participarem do Projeto de Expansão e Consolidação do Saúde da Família-Proesf. Diário Oficial da União 2003; 23 abr. [acessado 2008 jun]. Disponível em: http://dtr2002.saude. gov.br/proesf/

12. Brasil. Portaria no 892 , de 13 de maio de 2004. Aprova e habilita os municípios para participarem do Projeto de Expansão e Consolidação do Saúde da Família-Proesf. Diário Oficial da União 2003; 14 mai. [acessado 2008 jun]. Disponível em: http://dtr2002. saude.gov.br/proesf/

13. Brasil. Portaria no 1.080 , de 4 de julho de 2005. Aprova, habilita e estabelece valor ao município de Luziânia/GO para participar do Projeto de Expansão e Consolidação do Saúde da Família. Diário Oficial da União 2003; 5 jul. [acessaso 2008 jun]. Disponível em: http://dtr2002.saude.gov.br/proesf/

Artigo apresentado em 24/06/2008

Aprovado em 03/09/2008

Versão final apresentada em 10/10/2008 